\title{
O EDUCADOR MEDIADOR DO DISCENTE EM SUA FORMAÇÃO: A ARTE DO CUIDAR DO HUMANO
}

\author{
Sônia Maria Vicente Cardoso ${ }^{1}$ \\ ${ }^{1}$ Doutora em Educação. Docente do Programa de Mestrado em educação da UNOESTE
}

\section{RESUMO}

O texto reflete sobre o significado da relação docente-discente no âmbito do cuidar do ser humano. Aborda ainda o papel de formadora do caráter pessoal que a educação, e os docentes, como veículo de disseminação da mesma, possui, ou deveria possuir; preparando os alunos para comportarem-se diante do mundo como indivíduos plenos, capazes de compreenderem a si e aos seus semelhantes, de desempenharem as atividades de sua profissão com o máximo de respeito e cuidado em relação ao próximo.

Palavras-chave: Educador, educador-mediador, formação do estudante, cuidado do humano, relação professor-estudante.

\section{THE EDUCATOR AS MEDIATOR OF THE STUDENT IN HIS EDUCATION: THE ART OF HUMANE CARING}

\begin{abstract}
This paper is a reflection about the significance of student-teacher relationship and its integration with the human care. Also, the text the role of education, that must be the obligation to prepare the students to behavior just like an individuals able to understanding themselves and all kind of people, performing their activities with respect and zealous in relation the people.
\end{abstract}

Key Words: Educator, educator-mediator, student education, humane caring, teacher-student relationship. 


\section{INTRODUÇÃO}

Este artigo tem como principal objetivo refletir sobre o cuidar do humano, bem como, o desejar no sentido de ter um rumo, uma direção que ilumina o caminho do conhecimento das relações pedagógicas.

$\mathrm{E}$ aqui me recordo do educador Alves, (1994, p.31), quando afirma que o desejo é o foco centralizador de nossa grandeza e de nossa miséria... "Porque é do desejo que surgem a música, a literatura, a pintura, a religião e a ciência... Mas,também, é do desejo que surgem as ilusões, os rótulos e os preconceitos".

Para seguir o desejo como fonte de grandeza, faz-se necessário em primeira instância ter a "disposição de abertura", que é a possibilidade do homem abrir-se para o mundo, a humildade de "experienciar" a carência de conhecer algo, desprovido de conceitos pré-estabelecidos.

A disposição de abertura é condição e possibilidade do desejo, pois é o que diferencia o ser humano de outras espécies. $O$ animal tem carência, como sentir fome e sede, mas essa necessidade é determinação de sua espécie, enquanto para o homem o desejo é movimento, é fluidez, é buscar um sentido para a sua vida, é um retorno ao seu lar, ao seu projeto existencial.

Parece que, cada vez mais, torna-se difícil focalizar nossos desejos como fonte de grandeza, até porque as relações que se estabelecem no mundo atual orientam-nos para o individualismo, o distanciamento; coloca-nos numa condição de podermos ser catalogados, pré-julgados, tornando-nos menos acolhedores conosco e com os outros. O espelho mostra como somos, mas muitas vezes insistimos em enxergá-lo embaçado, por acomodação, conformismo ou preguiça e deixamos de lado nossos apelos.

Este texto vem abrir-se a um apelo: o de desejar compreender a multiplicidade dos sentidos existenciais que envolvem o cuidar do humano, o educador e o aluno, coparticipantes desse processo.

$O$ processo de aprendizagem em sala de aula na graduação, principalmente, é marcado singularmente pelo aspecto de capacitação profissional, privilegiando-se informações técnicas e treinamento para o exercício competente, técnico, de uma profissão, sem preocupação, espaço e oportunidade para $\mathrm{o}$ crescimento $\mathrm{e}$ desenvolvimento humanos. Nitidamente, tem-se a impressão de que os aspectos educacionais das pessoas deveriam ter sido trabalhados nas escolas de Ensino Fundamental e Médio. A Universidade deveria preocupar-se em formar o profissional competente.

Nós que em nossa prática educativa diária, temos a oportunidade de vivenciar o mundo acadêmico e o mundo do cotidiano profissional, por vezes sentimos que, de algum modo, são mundos distintos. Entretanto, temos bastante presente a necessidade de construirmos ligações a fim de que um mundo possa (in)formar e ser (in)formado pelo outro.

Há um senso de disparidade entre o que sabemos e o que fazemos, pois 
sentimos a premência de prover um cuidado de qualidade. Entretanto, de certa forma, não somos livres em propor o que entendemos como adequado. Constata-se que o cuidar do humano não é valorizado pelas instituições, constituindo-se em um problema para a profissão. Um exemplo disso está na ação do cuidado humano que deveria estar mais centrado na valorização à saúde ao invés da ênfase dada ao cuidado à doença.(Waldow, 1995, p.110)

Encontramos contradições e situações extremamente complexas a serem enfrentadas por nós em nosso dia-a-dia do ensino e do cuidado, as quais exigem que busquemos meios para informar os nossos discentes como se conduzirem frente às situações imprevisíveis da prática. Sentimos a necessidade de refletir e agir em direção ao nosso objetivo de melhor expressar e unificar a teoria que fundamenta a nossa prática, ensino e cuidado humano.

Schmarczek (1992, p.97) afirma que a fundamentação da prática deveria explicar o que se faz e como se faz. Entretanto, nem sempre a fundamentação está cientificamente comprovada, podendo basear-se em mitos, crenças e rotinas ou advir da experiência e conhecimento de outros e, ainda, muitas vezes o conhecimento é aplicado sem um prévio estudo do contexto o qual o mesmo será utilizado.

A sala de aula é instante inovador na vida da pessoa, espaço de surgimento de novas mediações, quando as contradições apresentam-se, encontros e evidências se destroem, momentos de crise e ruptura com o mundo dos valores familiares afloram. Sala de aula como afirmação de um novo começo na ordem das coisas (Masetto, 1992, p.71).

Mockaitis (2002, p.47), acredita que um educador de verdade, é aquele que mergulha na história dos seres humanos por trás dos alunos, para compreender sua real situação e poder discernir qual a melhor forma de mostrar a eles que ele se importa, que os vê, que os ouve, e se quiserem falar, que estará a sua mão. Essa necessidade de enxergar além, e demonstrar interesse, gera bons frutos, pois estabelece entre nós, muitos elos de comunicação e principalmente de confiança.

A contribuição de Boff (1999, p.35), diz que sem o cuidado, recebido ou doado, o homem deixa de "experenciar" sua humanidade e, se buscar construir sua vida em isolamento, verá que estará fadado ao fracasso absoluto, pois, existindo "realisticamente" tamanha interdependência entre todos, menosprezá-la pode levar à perda do sentido holístico da vida. A pessoa que vive esta situação pode acabar por morrer física ou psicologicamente.

O cuidado é algo que deve ser entendido muito além de um simples ato, por consolidar uma atitude revestida de significância e significado.

Conforme Waldow (1998, p.78), o cuidado ativa um comportamento de compaixão, de solidariedade, de ajuda no sentido de promover o bem. Neste sentido, os profissionais de saúde que visam o bemestar do paciente, a sua integridade moral e a sua dignidade como pessoa deve possuir intencionalmente no ato de cuidar. 
Um novo caminho dentro da saúde é trazido por Mayeroff (1990, p.49), no qual articula-se o conceito de cuidado no sentido relacional, enfocando-o do ponto de vista existencial filosófico. O autor afirma que o cuidar é um compromisso que a pessoa assume com o outro. Num processo que ajuda o outro a crescer, a idéia é que esse ser venha a cuidar também de algo ou de alguém, assim como de si mesmo. Ao "experenciar" o outro ou a uma idéia, não há dominação ou manipulação, apenas confiança.

O autor acima diz ainda que[...] para cuidar de outra pessoa, devo ser capaz de entendê-la e ao seu mundo como se estivesse dentro deste... Devo ser capaz de estar com ela em seu mundo, 'entrar' nesse mundo, para sentir de 'dentro' como é a vida para ela, o que se esforça para ser, e do que precisa para crescer.

Conforme referido por Buber (1987, p.68), o ser humano distingue-se por sua relação com os outros seres e/ou objetos. A relação com outro ser humano é um estado em que um reconhece o outro como sujeito e com ele se importa.

Quando um elo de confiança se estabelece entre docente e discente, estes aproveitam para desabafar seus sofrimentos, temores, angústias e solidão. Este elo é uma via de mão dupla, pois eles aproveitam para demonstrar carinho, apreço e gratidão.

Negar este caminho de comunicação seria virar as costas a todos os princípios humanos, morais, profissionais e éticos. Seria negar a diretriz primeira de um professor educador: $O$ aluno está em primeiro lugar, todo sistema educacional existe por ele e para ele.

Antes de tudo, o aluno é uma pessoa. Separar a pessoa, do aluno é transformar a educação em linha de produção mecanizada. E o melhor de um educador não está nos seus conhecimentos acadêmicos, mas na inabalável certeza de que ensinar e aprender são os dois lados da mesma moeda. É uma parceria.

\section{O CUIDADO HUMANO E A EDUCAÇÃO}

A minha experiência, somada à vivência inerente ao ser educadora e profissional da educação e trabalhando não só na Educação, mas também, na Saúde, mais especificamente na Odontologia, vinculada ao fenômeno do cuidar - tornou-me cada vez mais sensível para olhar o cuidado do humano com base em uma atitude fenomenológica.

Logo, tomando como um tema a ser considerado, o "cuidar do humano e o fenômeno educação" traz-nos à vista a evidência de ser o lugar onde, com primazia, nos defrontamos com a relação homemhomem. O que por primeiro enxergamos na educação é "o homem-sendo-com-os-outroshomens" de uma maneira particular.

Este "sermos-uns-com-os-outros" é o que se oferece como a "oportunidade" da educação. Mas o que de imediato evidenciase e, talvez, em razão mesmo de sua obviedade, é aquilo com que menos nós temos preocupado em especular a respeito do fenômeno educação.

Se a educação não é algo que "inventamos", mas que encontramos como 
um modo de "sermos-uns-com-os-outros", qual a razão de nos preocuparmos com ela? Para que nos envolvemos com ela e o que dela queremos? Se a educação nos fosse indiferente, certamente não teríamos criado tantos "centros educacionais". A multiplicidade deles nos mostra que a educação é algo muito importante, mas qual é, explicitamente, essa importância? Ainda mais, por que lançamos nela a possibilidade da autenticidade do existir?

Devemos nos voltar a ela recuperando o que nela se mostra de mais fundamental. $O$ educar é o espaço onde os homens estão sendo uns com os outros. Se a educação implica a relação homem-homem como relação básica, isto já nos está dizendo que se trata da relação dos homens entre si e não dos homens com outros entes que não são ser-aí também.

A consolidação de minha inquietação configurou e clareou o objetivo relacionado a este artigo voltado para desenvolvimento do tema: o educador mediador do discente em sua formação: a arte do cuidar do humano.

Para desvelar este fenômeno pela ótica de quem experiência e recebe o cuidado, optei por escrever com o propósito de Compreender como o docente exerce essa mediação para que este cuidar do humano seja sentido, seja percebido.

A busca de um caminho que possa vir a contribuir para a instalação e fixação de novos paradigmas do cuidar do humano, numa dinâmica viva que se concretiza na modificação da postura do educador de "ensinante" para "estar com", de transmissor para a atitude de troca, através de uma ação conjunta. Revela-se na seleção de estratégias que desenvolvam a pessoa, o indivíduo, o sujeito de iniciativa e o grupo (equipe, integração e socialização); que favoreçam a participação no processo e na criatividade.

O meu caminhar acadêmico induziu-me a um novo olhar, uma nova atitude, na busca pelo atendimento do fenômeno do cuidar do humano, com base na vivência do outro, em uma dimensão existencial, ou seja, por meio de uma abordagem compreensiva, de modo que me possibilitasse compreender a dimensão não somente da minha experiência profissional, mas também a dos demais sujeitos.

Fica-nos claros, que os motivos do fazer foram dois ingredientes jamais dissociados da vida: a experiência e a sensibilidade. A fenomenologia contempla, além do rigor metodológico, também esses ingredientes.

A fenomenologia é um movimento que busca interrogar os fenômenos do cotidiano, que abarca o homem na sua existencialidade, utilizando como caminho o método fenomenológico, que nos conduz a ver o que simplesmente se mostra obscuro, oculto e do avesso.

Esse interrogar se fundamenta na compreensão das relações que buscamos pôr em "descoberto", e não simplesmente na explicação casuística dos fatos estudados.

Assim, os fenômenos são observados, aproximados, quantas vezes se fizerem necessárias, em todos os sentidos, "andando em volta de".

Atuar dessa forma vai permitir ir ao encontro do outro, tão profundamente quanto 
possível, bem como lhe penetrar no âmago e avaliar suas preocupações, para, desta forma, permitir-Ihe encontrar suas próprias respostas.

A atitude fenomenológica, enquanto ferramenta de trabalho auxilia no entendimento do sentido existencial dos educadores do cuidar do humano além da sala de aula. A fenomenologia abre novos horizontes para compreender o modo constitutivo dos docentes como mediadores na formação do discente, na sua maneira de relacionar-se, de valorar, de julgar e de estar no mundo, e no mundo acadêmico.

Ao trabalhar este artigo, percebe-se que necessitaríamos de apoiar-nos em um referencial teórico que nos permitisse compreender o significado do cuidar do humano em sala de aula por meio do vivido pelos educadores.

Optamos por desenvolver esta temática pelo ângulo da visão existencial. Desse modo, encontramos no pensamento filosófico de Martin Heidegger o fio norteador e condutor para a análise e a interpretação dos significados, uma vez que Heidegger (1993; 1998), em seu estudo sobre existencialismo, não separa a razão da emoção e, sim, questiona o modo de ser na existência, elucidando que esse ser engloba a totalidade que lhe é possível apreender em seu ser com base na "mundaneidade", ou seja, no modo essencial de viver, que se fundamenta de diversas maneiras.

O objetivo do trabalho coletivo do educador deverá estar sempre voltado para encontrar, juntamente com seus pares, pistas que permitam modificar o clima e a situação da sala de aula de graduação, de forma que, o cuidado do humano possa tornar-se um cuidado que ative um comportamento de compaixão, de solidariedade, de ajuda no sentido de promover o bem.

\section{CONCLUSÃO}

Neste sentido, os docentes que visam o bem-estar do discente, a sua integridade moral e a sua dignidade como pessoa devem possuir intencionalidade no ato do cuidar do humano. Um novo caminho dentro da docência é trazido para reflexão, no qual articula-se o conceito de cuidado no sentido relacional, enfocando-o do ponto de vista existencial filosófico.

O cuidar do humano é um compromisso que a pessoa assume com o outro. Num processo que ajuda o outro a crescer, a idéia é que esse ser venha a cuidar também de algo ou de alguém, assim como de si mesmo.

\section{REFERÊNCIA BIBLIOGRÁFICA}

ALVES R. Filosofia da Ciência, CAMPINAS, SP: PAPIRUS, 1994.

BOFF L. Saber cuidar. Ética do humano compaixão pela terra. Petrópolis: Vozes; 1999.

BUBER M. Eu e tu. Trad. de Newton Aquiles Von Zuben. 5. ${ }^{a}$ ed. São Paulo: Centauro; 1987.

HEIDEGGER M. Ser e tempo. Trad. por Márcia de Sá Cavalcanti. 3. ${ }^{a}$ ed. Petrópolis, Vozes, 1993. v.2. 
HEIDEGGER M. Ser e tempo. Trad. por Márcia de Sá Cavalcanti. 7. a ed. Petrópolis, Vozes, 1998. v.1.

MOCKAITIS C, POKLADEK DD. História de uma professora a autobiografia no processo psicoterapêutico. Santo André, SP: Alpharrabio, 2002.

MASETTO M T. Aulas vivas. Tese (e prática) de livre docência. São Paulo: MG editores associados, 1992.

SCHMARCZEK M. Reflexões sobre o pesquisar para educar. Rev.da Escola de Enfermagem da USP, São Paulo, v.26, n. ${ }^{\circ}$ especial, p 95-100, 1992.

WALDOW VR, LOPES MJM, MEYER DE. Cuidado humano: o resgate necessário. Porto Alegre: Sagra Luzzatto; 1998.

WALDOW VR, LOPES MJM, MEYER DE. Maneiras de cuidar maneiras de ensinar. A enfermagem entre a escola e a prática profissional. Porto Alegre. Sagra Luzzatto; 1995. 